\title{
Characterization of Histone Genes from the Bivalve Lucina Pectinata
}

\author{
Ingrid M. Montes-Rodríguez ${ }^{1}$, Yesenia Rodríguez-Pou ${ }^{2}$, Ricardo R. González-Méndez ${ }^{3}$ (D), \\ Juan Lopez-Garriga ${ }^{4}$, Alexander J. Ropelewski ${ }^{5}$ and Carmen L. Cadilla ${ }^{2, *}$ \\ 1 Comprehensive Cancer Center University of Puerto Rico. P.O. BOX 363027, \\ San Juan 00936-3027, Puerto Rico; imontes@cccupr.org \\ 2 Department of Biochemistry, School of Medicine, University of Puerto Rico-Medical Sciences Campus, \\ P.O. Box 365067, San Juan 00936-5067, Puerto Rico; yesenia.rodriguez8@upr.edu \\ 3 Department of Radiological Sciences, School of Medicine, University of Puerto Rico-Medical \\ Sciences Campus, P.O. Box 365067, San Juan 00936-5067, Puerto Rico; ricardo.gonzalez7@upr.edu \\ 4 Department of Chemistry, Faculty of Arts and Sciences, University of Puerto Rico-Mayagüez Campus, \\ P.O. Box 9019, Mayagüez 00681-9019, Puerto Rico; juan.lopez16@upr.edu \\ 5 Pittsburgh Supercomputing Center 300 South Craig Street Pittsburgh PA 15213; ropelews@psc.edu \\ * Correspondence: carmen.cadilla@upr.edu; Tel.: +1-787-754-4366
}

Received: 31 August 2018; Accepted: 27 September 2018; Published: 2 October 2018

\begin{abstract}
Lucina pectinata is a clam that lives in sulfide-rich environments and houses intracellular sulfide-oxidizing endosymbionts. To identify new Lucina pectinata proteins, we produced libraries for genome and transcriptome sequencing and assembled them de novo. We searched for histone-like sequences using the Lucina pectinata histone $\mathrm{H} 3$ partial nucleotide sequence against our previously described genome assembly to obtain the complete coding region and identify $\mathrm{H} 3$ coding sequences from mollusk sequences in Genbank. Solen marginatus histone nucleotide sequences were used as query sequences using the genome and transcriptome assemblies to identify the Lucina pectinata $\mathrm{H} 1$, $\mathrm{H} 2 \mathrm{~A}, \mathrm{H} 2 \mathrm{~B}$ and $\mathrm{H} 4$ genes and mRNAs and obtained the complete coding regions of the five histone genes by RT-PCR combined with automated Sanger DNA sequencing. The amino acid sequence conservation between the Lucina pectinata and Solen marginatus histones was: 77\%, 93\%, 83\%, 96\% and 97\% for $\mathrm{H} 1, \mathrm{H} 2 \mathrm{~A}, \mathrm{H} 2 \mathrm{~B}, \mathrm{H} 3$ and $\mathrm{H} 4$, respectively. As expected, the $\mathrm{H} 3$ and $\mathrm{H} 4$ proteins were the most conserved and the $\mathrm{H} 1$ proteins were most similar to $\mathrm{H} 1$ 's from aquatic organisms like Crassostrea gigas, Aplysia californica, Mytilus trossulus and Biomphalaria glabrata. The Lucina pectinata draft genome and transcriptome assemblies, obtained by semiconductor sequencing, were adequate for identification of conserved proteins as evidenced by our results for the histone genes.
\end{abstract}

Keywords: histone gene; gene variants; mollusk; gene evolution; bioinformatics; next-generation sequencing; Sanger sequencing

\section{Introduction}

In eukaryotes and some archaebacteria, DNA is found as a nucleoprotein complex called chromatin, associated with histones that allows for the high levels of compaction of genomic DNA within the limited space of the cell nucleus [1]. Histones are basic proteins, four of them (H3, H4, H2A and H2B) form the histone octamer that DNA winds around to form the nucleosome, the fundamental structural unit of chromatin [2]. A fifth lysine-rich histone ( $\mathrm{H} 1$ and related proteins) binds the nucleosome at the entry and exit sites of the DNA, locking the DNA into place and allowing the development of higher order structures. Histones also play a major role in modulating changes in chromatin structure, impacting gene regulation, mostly through their post-translational modifications [3]. 
The core histones exist as dimers; they all possess the histone fold domain: three alpha helices linked by two loops. This helical structure allows for interaction between distinct dimers. The histone H1 family stands out among histone for being the most diverse [3]. Though they are relatively conserved, especially in their central globular domain, which consists of a 3-helix "winged helix" fold containing a classical helix-turn-helix motif, they are the most variable histones across different species [4]. Their sequence complexity may be related to subtype functional differentiation [4]. Much has been learned about histone H1 from studies on purified chromatin fibers. Ionic extraction of these linker histones from native chromatin promotes its unfolding under hypotonic conditions [5]. It is still unknown if $\mathrm{H1}$ promotes a solenoid-like chromatin fiber, in which the exposed linker DNA is condensed, or if it merely promotes a change in the angle of adjacent nucleosomes without affecting the linker's length [6]. Although the long-term evolution of the H1 family has been studied in deuterostomes in previous years, the invertebrate $\mathrm{H} 1$ proteins, especially in animals such as mollusks, still remain less studied [7]. It has been proposed that $\mathrm{H} 1$ histone genes are subject to birth-and-death evolution with strong purifying selection, which may explain the existence of replication-dependent (RD) and replication-independent $\mathrm{H} 1$ isoforms [7].

The objective of this work is to characterize the histone complement and better understand the evolution of proteins like the $\mathrm{H} 1$ family using the clam Lucina pectinata (L. pectinata) as a model system for invertebrates. L. pectinata is a bivalve that lives in sulfide-rich environments and houses intracellular sulfide-oxidizing endosymbiotic bacteria. Since it has been proposed that histone H1 isoforms may arise by functional differentiation, the ability of this clam to exist in its tropical but extreme environment may have given rise to different subtypes.

In order to identify new proteins in this organism, a draft genome was assembled from a genomic library and characterized using semiconductor sequencing chemistry [8]. To validate the genome assembly and identify histone genes for L. pectinata, a search for Histone-like sequences was performed using the known partial coding sequence of histone $\mathrm{H} 3$ from $L$. pectinat $a$ and the nucleotide sequences of the Histone H1, H2A, H2B, H3 and H4 from the clam Solen marginatus (S. marginatus) as query sequences using the draft genome as library [1].

For evaluation of the evolutionary aspects of this study, we focused on the L. pectinata histone H1 variant sequences (H1_A and H1_B) that were obtained, to determine if these variants have a common ancestor found in other marine organisms and to study their evolution among different species. These findings contribute to the study of functional differentiation of the histone $\mathrm{H} 1$ family among mollusk species.

\section{Materials and Methods}

\subsection{Biological}

Ethics statement: The clam Lucina pectinata houses symbiotic bacteria and lives in shallow sea waters of mangrove swamps in Southwestern Puerto Rico, whose sediments contain high sulfide concentrations. Juvenile L. pectinata clams were purchased from a local fisherman in the town of Cabo Rojo, PR. Typically, when our collaborating fisherman harvests the clams in the mangroves of Cabo Rojo for research purposes, they are kept in buckets filled with mangrove mud and seawater until they were picked up the same day they were harvested. L. pectinata is not an endangered or protected species, hence, no specific permits were required to obtain the clams since they are a local food item. Clams were transported in seawater containing mud extracted from the site where they were harvested, until either used for isolation and purification of DNA or RNA or until the tissues were harvested and snap frozen for subsequent protein isolation.

\subsection{DNA and RNA Isolation}

Genomic DNA (gDNA) from L. pectinata was extracted from $100 \mathrm{mg}$ of mantle tissue, in order to avoid endosymbiont contamination, using the QIAGEN Genomic-tip 100/G (QIAGEN, 
Inc. Germantown, MD, USA) following the manufacturer's instructions for DNA isolation from animal tissue. Total gDNA was quantified with the Nanodrop 2000c (Thermo Fisher Scientific, Inc. Wilmington, DE, USA), and the concentration of double stranded DNA with the Qubit dsDNA HS Assay Kit from Invitrogen in the Qubit ${ }^{\circ} 2.0$ Fluorometer (Invitrogen, Carlsbad, CA, USA), as recommended by the manufacturer's instructions.

Several clams were carefully dissected within $24 \mathrm{~h}$ after clam harvest for RNA isolation. The rest of the clams were put in a fish-tank with seawater and a pump filter. They were fed phytoplankton twice a week. At 108 days they were snap frozen in liquid nitrogen and stored at $-80{ }^{\circ} \mathrm{C}$ until processed. Ctenidia RNAs were isolated from three clams harvested from their natural environment and three clams kept in a fish tank for 108 days. RNA was extracted from the ctenidia tissue using TRIzol reagent (Sigma-Aldrich, St. Louis, MO, USA), following the modified procedure of RNA isolation described by Chomczynski [9], as recommended by the manufacturer. To improve the $\mathrm{A}_{260} / \mathrm{A}_{230}$ ratio of the RNA samples, RNAs were extracted with 1-Butanol followed with two consecutive diethyl ether extractions [10], in order to remove traces of TRIzol reagent.

\subsection{Whole Genome Sequencing}

A genomic library for Ion Proton sequencing was created using the IonPlus Fragment Library kit from Life Technologies (Carlsbad, CA) , according to the Ion Xpress ${ }^{\mathrm{TM}}$ Plus gDNA Fragment Library Preparation protocol following the manufacturer's instructions (Publication Number MAN0009847). Briefly, $1 \mu \mathrm{g}$ of high molecular weight mantle gDNA was fragmented by sonication using the Bioruptor®UCD-200 sonication device (Denville, NJ, USA). After fragmentation, the DNA was end-repaired and purified followed by the adaptor ligation, nick-repair, and purification of the ligated DNA as indicated in the manufacturer's manual. The ligated DNA was size-selected using the Pippin Prep ${ }^{\mathrm{TM}}$ instrument (SAGE Science, Beverly, MA, USA) with the pre-cast $2 \%$ agarose gel (ethidium bromide-stained) cassettes and marker B (Sage Science, Beverly, MA). Then, the sample was purified with $1.5 \times$ volumes of Agencourt AMPure ${ }^{\circledR X P}$ Reagent (Beckman Coulter Inc., Indianapolis, IN) and its concentration determined by quantitative PCR (qPCR) using the Ion Library Quantitation Kit (Life Technologies, Carlsbad, CA, USA), as recommended by the manufacturer. The sample was amplified with the Platinum ${ }^{\circ} P C R$ Super Mix High Fidelity (Invitrogen, Carlsbad, CA) reaction mixture and the Library Amplification Primer Mix, supplied by the IonPlus Fragment Library kit and purified. Afterwards, the library was analyzed on the Agilent ${ }^{\circledR} 2100$ Bioanalyzer ${ }^{\circledR i n s t r u m e n t}$ (Agilent Technologies, Santa Clara, CA) with an Agilent High Sensitivity DNA Kit to evaluate size distribution of the final library and the library concentration was determined by qPCR with the Ion Library Quantitation Kit (Life Technologies, Carlsbad, CA, USA). The DNA fragment size distribution was ca. 200 base pairs (bp). The emulsion PCR step and enrichment of the library were carried out in the Ion OneTouch ${ }^{\text {TM }} 2$ System and in the Ion OneTouch ${ }^{\text {TM }}$ ES System (Life Technologies, Carlsbad, CA), respectively, using the Ion PI ${ }^{\mathrm{TM}}$ Template OT2 200 Kit v3 from Life Technologies following the Ion PITM Template OT2 200 Kit v3 User Guide (Publication \# MAN0009133). Next, the sample was run in the Ion Proton ${ }^{\mathrm{TM}}$ Sequencer using the Ion $\mathrm{PI}^{\mathrm{TM}}$ Chip V2 (Life Technologies, Carlsbad, CA). The sample was prepared using the Ion PI ${ }^{\mathrm{TM}}$ Sequencing 200 Kit v3 (Life Technologies, Carlsbad, CA) following the Ion PI ${ }^{\mathrm{TM}}$ Sequencing 200 Kit v3 User Manual (Publication Number MAN0009136) and run in the Ion Proton ${ }^{\mathrm{TM}}$ Sequencer (Life Technologies, Carlsbad, CA).

The sequence read data was analyzed on the Pittsburgh Supercomputing Center's Blacklight system. The sequence reads were submitted to the NCBI Sequence Read Archives (SRA) and assigned Run number SRR7822584, SRA Sample SRS3768289 and SRA Study SRP161589. To create a draft de novo assembly, an unpaired low-coverage Ion Torrent dataset was selected according to the output and quality of data available. The reads were quality control trimmed and filtered using the Sickle Windowed Adaptive Trimming Tool, discarding reads with $<75$ bases in length and used a quality score threshold of 15. Then, the trimmed data was assembled with MIRA Version 4.0.2 as 
described [8]. The genome assembly was submitted to the NCBI Genbank database, with submission number SUB4511435, the GenBank accession number is pending.

\subsection{RNA Sequencing}

Transcriptome libraries were made using the Ion Total RNA-Seq Kit v2 from Life Technologies following the manufacturer's instructions (Publication Number 4476286). The quality of RNA was verified by running the Agilent RNA 6000 Nano Kit in the Bioanalyzer®2100 instrument following the RNA 6000 Nano Kit user manual. Briefly, 0.5-1 $\mu \mathrm{g}$ of total RNA were used as starting material. We reduced ribosomal RNA (rRNA) content using the Low Input RiboMinus ${ }^{\mathrm{TM}}$ Eukaryote System V2 (Life Technologies, Carlsbad, CA), following the kit user guide (Publication Number MAN 0007160). The qualitative analysis of rRNA removal was assessed comparing the total RNA profiles before and after the removal of rRNA using the Agilent RNA 6000 Pico Kit in the Bioanalyzer ${ }^{\circledR 2100 ~ i n s t r u m e n t ~(A g i l e n t ~ T e c h n o l o g i e s, ~ S a n t a ~ C l a r a, ~ C A, ~ U S A) ~ a s ~ r e c o m m e n d e d . ~ I n ~ t h e ~}$ clam Lucina pectinata, the 28SrRNA fragment is not observed due to presence of a break point in the rRNA structure which converts the $28 \mathrm{~S}$ rRNA to two fragments that migrate similarly to the $18 \mathrm{~S}$ rRNA in gel electrophoresis. Hence, we assessed the reduction of rRNA content by analysis of the $18 \mathrm{~S}$ rRNA peaks content versus the lower molecular weight abundant RNAs. Bioanalyzer traces showed that five out of the six RNA samples used for RNA sequencing had rRNA peaks eliminated and one of the samples had a $6.3 \times$ reduction of rRNA content, demonstrating the utility of the RiboMinus kit employed for rRNA reduction in this type of organism. Then, these samples were fragmented by RNase III digestion for $3 \mathrm{~min}$ at $37^{\circ} \mathrm{C}$ and purified following the Ion Total RNA-Seq Kit v2 (Life Technologies, Carlsbad, CA) manual specifications. Sample yield and size distribution were assessed using the RNA 6000 Pico Kit with the Agilent 2100 Bioanalyzer ${ }^{\circledR}$ instrument. Two RNA samples from each environment (4 in total) were barcoded using Ion Xpress ${ }^{\mathrm{TM}}$ RNA-Seq Barcode 1-16 Kit (Life Technologies, Carlsbad, CA). The remaining two RNA samples (one from each environment) were run on individual IonProton PI chips. Emulsion PCR and enrichment steps were carried out in the Ion OneTouch ${ }^{\mathrm{TM}} 2$ System and the Ion OneTouch ${ }^{\mathrm{TM}}$ ES System (Life Technologies, Carlsbad, CA), respectively, using the Ion PI ${ }^{\mathrm{TM}}$ Template OT2 200 Kit v3 from Life Technologies following the Ion PI ${ }^{\mathrm{TM}}$ Template OT2 200 Kit v3 User Guide (Publication Number MAN0009133). Each sample was run in the Ion Proton ${ }^{\mathrm{TM}}$ Semiconductor Sequencer using the Ion $\mathrm{PI}^{\mathrm{TM}}$ Chip V2 (Life Technologies, Carlsbad, CA). The samples were prepared using the Ion PI ${ }^{\mathrm{TM}}$ Sequencing $200 \mathrm{Kit}$ v3 (Life Technologies, Carlsbad, CA) following the user manual (Publication Number MAN0009136). A total of three chips (one chip with the four barcorded libraries and the other two individual samples) were loaded and run in the Ion Proton ${ }^{\mathrm{TM}}$ Sequencer (Life Technologies, Carlsbad, CA). Sequence reads from all chips were combined in order to assemble a reference transcriptome de novo.

The Ion Torrent data was analyzed on the Pittsburgh Supercomputer Center's Blacklight system, a high-performance computing system available through the National Science Foundation (NSF) Extreme Science and Engineering Discovery Environment (XSEDE) Program. A transcriptome reference was assembled de novo using Trinity software version r2014-04-13p1 [11]. All six single ended read samples were combined to create a single data file for the assembly run. The default parameters for single ended read sequences were used to create the assembly [11]. Raw read sequence data were deposited in NCBI's sequence read archive (SRA) database: BioProject PRJNA282817. The Transcriptome Shotgun Assembly project has been deposited at DDBJ/EMBL/GenBank under the accession GGWH00000000. The version described in this paper is the first version, GGWH01000000.

\subsection{Sequence Similarity Searches and Validation of Semiconductor Sequencing Results}

In order to find the histone sequences in our draft genome, we searched for homologous sequences from an organism that was evolutionary close to L. pectinata. For this reason, we used the histone nucleotide sequences from another clam, S. marginatus using the Basic Local Alignment and Search Tool (BLAST) for nucleotide searches, BLASTN [12-14], optimized for somewhat similar sequences, using 
the known gene nucleotide sequences of the histone 1 (H1) (GenBank accession number FJ595834.1), histone 2A (H2A) (GenBank accession number FJ595835.1), histone 2B (H2B) (GenBank accession number FJ595836.1), histone 3 (H3) (GenBank accession number FJ595837.1) and histone 4 (H4) (GenBank accession number FJ595838.1) from the clam Solen marginatus [1] and the partial coding sequence of the L. pectinata histone H3 (GenBank accession number GQ980264.1) as query sequences. We chose the sequences that produced a good match (with identities $>68 \%$ ) and searched for open reading frames (ORF) using the ORF Finder tool from NCBI performing a six-frame translation of each of the nucleotide sequences [15]. Each of the translated sequences of adequate length for each type of histone were analyzed with the protein BLAST (BLASTP) tool, using default parameters against the non-redundant protein database $[14,15]$. We selected those sequences that produced a complete protein (comparing histone sizes across different organisms) and had histone conserved domains. In order to amplify these regions, we designed forward and reverse primers for each of these nucleotide sequences using the Primer3Plus software [16] ensuring that the complete coding region was included in the regions amplified with both primers (see Table 1). The RT-PCRs were carried out using the One®Step RT-PCR kit (QIAGEN, Germantown, MD) following the manufacturer's instructions. The reaction consisted of 1X OneStep Buffer, 0.4 mM dNTP mix, $0.6 \mathrm{mM}$ of each primer (forward and reverse), $5 \mu \mathrm{L}$ of Q-solution, $1 \mu \mathrm{L}$ QIAGEN Enzyme Mix in a total volume of $25 \mu \mathrm{L}$ and $135 \mathrm{ng}$ of L. pectinata ctenidia RNA. The cycling parameters were: $50^{\circ} \mathrm{C}$ for $30 \mathrm{~min}, 95^{\circ} \mathrm{C}$ for $15 \mathrm{~min}, 40$ cycles of $94{ }^{\circ} \mathrm{C}$ for $30 \mathrm{~s}, 60{ }^{\circ} \mathrm{C}$ for $45 \mathrm{~s}$ and $72{ }^{\circ} \mathrm{C}$ for $1 \mathrm{~min}$, followed by $72{ }^{\circ} \mathrm{C}$ for $10 \mathrm{~min}$. The RT-PCR products were evaluated in a $1 \%$ agarose gel, purified using QIAGEN PCR purification kit and sequenced on both strands in an ABI 310 automated DNA sequencer using dye terminator chemistry (Big Dye V3 DyeTerminator Sequencing kit, Applied Biosystems, Foster City, CA).

Table 1. Primers used for the amplification of histone-like sequences from Lucina pectinata RNA by RT-PCR.

\begin{tabular}{|c|c|c|}
\hline Target Sequence & Forward Primer & Reverse Primer \\
\hline Histone H1_A & 5'-GTCACGGCTCAATCCATAGT-3' & 5'-GTGTGATAAATGAGAAGGTGATAGAAG-3' \\
\hline Histone $\mathrm{H} 2 \mathrm{~A}$ & 5'-GGCGATGCCTCATATTCTTT-3' & 5'-AAAAAGGGCCGTTGAAAGTT-3' \\
\hline Histone H2B & 5'-CTTTGCGGAAAATTTGATGG-3' & 5'-GCGTTCCCTCATTCAGTGTT-3' \\
\hline Histone $\mathrm{H} 3$ & 5'-AAAAAGGGCCGTTATAGTGAG-3' & 5'-ACCAATCAGCGTTGTTTTCC-3' \\
\hline Histone $\mathrm{H} 4$ & 5'-AATAAGGGCCGTTTTCTTTTT-3' & 5'-CGGGTTCTTCAGTTCTCAGC-3' \\
\hline
\end{tabular}

\subsection{Histone Protein Extraction and Electrophoresis}

We isolated the histone proteins from ctenidia and mantle tissues using a Histone Extraction kit (Abcam) according to the manufacturer's instructions. First, the tissue sample was cut into small pieces $\left(1-2 \mathrm{~mm}^{3}\right)$ with a scalpel, followed by homogenization in one volume of Pre-Lysis buffer, (ca. $200 \mathrm{mg} / \mathrm{mL}$ ) in a glass Dounce homogenizer. All centrifugation steps were carried out in a refrigerated microcentrifuge (Eppendorf 5830R, Eppendorf North America, Hauppauge, NY, USA). The homogenate was transferred to a $15 \mathrm{~mL}$ conical tube and centrifuged at $3000 \mathrm{rpm}$ for $5 \mathrm{~min}$ at $4{ }^{\circ} \mathrm{C}$. The supernatant was removed and discarded and the pellet resuspended in three volumes of Lysis Buffer, incubated on ice for $30 \mathrm{~min}$, followed by centrifugation at $12,000 \mathrm{rpm}$ for $5 \mathrm{~min}$ at $4{ }^{\circ} \mathrm{C}$. The supernatant (containing acid-soluble proteins) was transferred into a new vial. Then, 0.3 volumes of the Balance-DTT Buffer were added immediately to the supernatant (e.g., $0.3 \mathrm{~mL}$ of Balance-DTT Buffer to $1 \mathrm{~mL}$ of supernatant). The samples were quantified in a Nanodrop 2000c by measuring the $A_{280}$.

Histone proteins were analyzed in a discontinuous sodium dodecyl sulfate (SDS) Polyacrylamide Gel Electrophoresis (PAGE) buffer system using the Mini-PROTEAN®System (BIO- RAD, Hercules, CA, USA) as recommended by Thoma and Kornberg [17]. We loaded $20 \mu \mathrm{g}$ of each sample, including calf thymus histones as controls (Sigma Aldrich, St. Louis, MO), which were dissolved in water at a final concentration of $10 \mu \mathrm{g} / \mu \mathrm{L}$. The gel was run for $120 \mathrm{~min}$ at $0.3 \mathrm{~A}$, constant current, fixed for $1 \mathrm{~h}$ in 50\% methanol and 10\% glacial acetic acid and stained (0.1\% Coomassie Brilliant Blue R-250, 
$50 \%$ methanol and $10 \%$ glacial acetic acid) for $20 \mathrm{~min}$ with gentle agitation. The gel was destained in a solution containing $40 \%$ methanol and $10 \%$ glacial acetic acid.

\subsection{Selection of Sequences from Different Species Related To The Histone H1_A Protein Sequence}

The L. pectinata $\mathrm{H} 1 \_\mathrm{A}$ and B amino acid sequences were derived from their nucleotide sequences. To determine the conservation of the H1_A amino acid sequence among species, a BLAST search was performed using the Universal Protein Resource (UniProt) Knowledge Base (UniProtKB) and UniProtKB/SWISS-PROT databases, where curated sequences selected ranged in identity from 80 to $50 \%$. The species selected are shown in Table S1 of the supplementary section. Once the species were selected, these sequences were downloaded as a text file in FASTA format, the L. pectinata H1_B query sequence was added, and a multiple sequence alignment was made.

2.8. Multiple Sequence Alignment of Histone H1 Proteins from Various Species and Phylogenetic Analysis of Histone H1 Proteins

We employed the Pittsburgh Supercomputing Center's BioU/Galaxy server to perform phylogenetic analysis. For the multiple sequence alignment of selected $\mathrm{H} 1$ proteins, a ClustalW alignment was performed using a BLOSUM30 matrix and a gap open/extension penalty of 10.0 and 0.1 , respectively. The alignments were visualized on the server and using Jalview [18]. The multiple sequence alignment was trimmed using the trimAl tool using the heuristic 'automated1'. Using the trimmed alignment, a consensus phylogenetic tree with 100 bootstrap replicates was generated using the PHYLIP suite of tools [19]. To generate multiple data sets of our input data, we employed the bootstrap and Seqboot using 100 replicates. To estimate phylogenies from protein amino acid sequences by maximum likelihood from our bootstrapped protein dataset, ProML was executed using 100 replicates, jumbling the sequence order (arranging our sequences in random order instead of arranging them in the order they were uploaded). Finally, the Consense tool in PHYLIP was used to generate an unrooted consensus tree using an extended majority rule [19].

The consensus tree was downloaded in Newick format, and visualized using the Interactive Tree of Life (iTOL, [20]) server.

\section{Results}

\subsection{Sequence Similarity Searches Identify Lucina Pectinata Histone Genes in Genome Assembly}

Our strategy to search for histone genes relied on the fact that histones have been highly conserved in evolution. $\mathrm{H} 4$ and $\mathrm{H} 3$ are highly conserved while H1, H2A and H2B are less conserved [21]. However, at the nucleotide level, the sequence conservation could be lower due to degeneration of the genetic code. We used the histone nucleotide sequences from $S$. marginatus to retrieve at least one nucleotide sequence for each histone gene with relatively high identities even at the nucleotide level: $69 \%, 77 \%, 77 \%, 82 \%$ and $80 \%$ for $\mathrm{H} 1, \mathrm{H} 2 \mathrm{~A}, \mathrm{H} 2 \mathrm{~B}, \mathrm{H} 3$ and $\mathrm{H} 4$, respectively (see Table 2). 
Table 2. Histone Nucleotide sequences identified from the BLASTN searches using the Lucina pectinata partial Histone H3 sequence and histone nucleotide sequences from the clam Solen marginatus as queries against the L. pectinata genome assembly.

\begin{tabular}{|c|c|c|c|c|c|c|c|c|c|c|c|}
\hline Query Seq-id & Subject Seq-id & $\%$ Identity & $\begin{array}{l}\text { Alignment } \\
\text { Length }\end{array}$ & $\begin{array}{c}\text { Number } \\
\text { of Mismatches }\end{array}$ & \# of Gaps & $\begin{array}{c}\text { Start } \\
\text { Query }\end{array}$ & End Query & $\begin{array}{c}\text { Start } \\
\text { subject }\end{array}$ & $\begin{array}{c}\text { End } \\
\text { Subject }\end{array}$ & E-value & Bit score \\
\hline L.pectinataH3 & Lucina_Clam2_rep_c512804 & 99.7 & 328 & 1 & 0 & 1 & 328 & 139 & 466 & 9.00E-173 & 589 \\
\hline S.margina-tus.H3 & Lucina_Clam2_rep_c512804 & 82.75 & 458 & 74 & 2 & 200 & 652 & 115 & 572 & 2.00E-135 & 466 \\
\hline S.margina-tus.H1 & Lucina_Clam2_c212178 & 68.98 & 432 & 92 & 12 & 251 & 670 & 1899 & 1498 & $1.00 \mathrm{E}-42$ & 159 \\
\hline S.margina-tus.H1 & Lucina_Clam2_rep_c490797 & 68.98 & 432 & 92 & 12 & 251 & 670 & 520 & 921 & $1.00 \mathrm{E}-42$ & 159 \\
\hline S.margina-tus.H1 & Lucina_Clam2_rep_c490798 & 68.98 & 432 & 92 & 12 & 251 & 670 & 420 & 821 & $5.00 \mathrm{E}-43$ & 159 \\
\hline S.margina-tus.H2B & Lucina_Clam2_c473960 & 76.92 & 429 & 89 & 5 & 171 & 593 & 690 & 266 & 9.00E-90 & 315 \\
\hline S.margina-tus.H3 & Lucina_Clam2_rep_c512805 & 81.37 & 424 & 73 & 3 & 234 & 652 & 1 & 423 & 9.00E-116 & 401 \\
\hline S.margina-tus.H2A & Lucina_Clam2_c411227 & 76.47 & 391 & 88 & 2 & 146 & 532 & 694 & 1084 & $6.00 \mathrm{E}-81$ & 286 \\
\hline S.margina-tus.H2A & Lucina_Clam2_c263014 & 76.67 & 390 & 88 & 1 & 146 & 532 & 52 & 441 & $1.00 \mathrm{E}-82$ & 291 \\
\hline S.margina-tus.H2A & Lucina_Clam2_c46738 & 68.51 & 362 & 107 & 2 & 151 & 507 & 241 & 600 & $6.00 \mathrm{E}-36$ & 136 \\
\hline S.margina-tus.H2B & Lucina_Clam2_c411226 & 79.2 & 327 & 65 & 1 & 171 & 497 & 417 & 740 & $4.00 \mathrm{E}-80$ & 282 \\
\hline S.margina-tus.H4 & Lucina_Clam2_c263013 & 79.62 & 319 & 65 & 0 & 147 & 465 & 555 & 873 & $9.00 \mathrm{E}-80$ & 282 \\
\hline S.margina-tus.H4 & Lucina_Clam2_rep_c482374 & 79.62 & 319 & 65 & 0 & 147 & 465 & 5 & 323 & $7.00 \mathrm{E}-80$ & 282 \\
\hline S.margina-tus.H4 & Lucina_Clam2_rep_c482375 & 79.31 & 319 & 65 & 1 & 147 & 465 & 46 & 363 & 4.00E-78 & 275 \\
\hline S.margina-tus.H1 & Lucina_Clam2_c353214 & 69.18 & 305 & 81 & 7 & 302 & 601 & 317 & 613 & $3.00 \mathrm{E}-27$ & 107 \\
\hline Solen.marginatus.H2A & Lucina_Clam2_rep_c481900 & 76.6 & 282 & 65 & 1 & 146 & 427 & 281 & 1 & $1.00 \mathrm{E}-57$ & 208 \\
\hline Solen.marginatus.H3 & Lucina_Clam2_rep_c482111 & 83.27 & 275 & 46 & 0 & 200 & 474 & 327 & 601 & 3.00E-82 & 289 \\
\hline Solen.marginatus.H3 & Lucina_Clam2_c3893 & 74.35 & 269 & 65 & 2 & 200 & 466 & 1111 & 845 & $5.00 \mathrm{E}-45$ & 168 \\
\hline Solen.marginatus.H2A & Lucina_Clam2_c155385 & 72.08 & 265 & 73 & 1 & 143 & 407 & 722 & 985 & $1.00 \mathrm{E}-37$ & 141 \\
\hline Solen.marginatus.H1 & Lucina_Clam2_rep_c482183 & 69.61 & 204 & 35 & 7 & 473 & 670 & 11 & 193 & 2.00E-19 & 82.4 \\
\hline
\end{tabular}


We also compared the predicted histone amino acid sequences from L. pectinata with those of S. marginatus (see Figure 1) and, as expected, sequence conservation at the protein level was even higher: 77\%, 93\%, 83\%, 96\% and 97\% for H1_A, H2A, H2B, H3 and H4, respectively. The overall properties of the L. pectinata histones were very similar to the S. marginatus counterparts (Table 3), having similar amino acid content, $\mathrm{pI}$ and molecular weight.

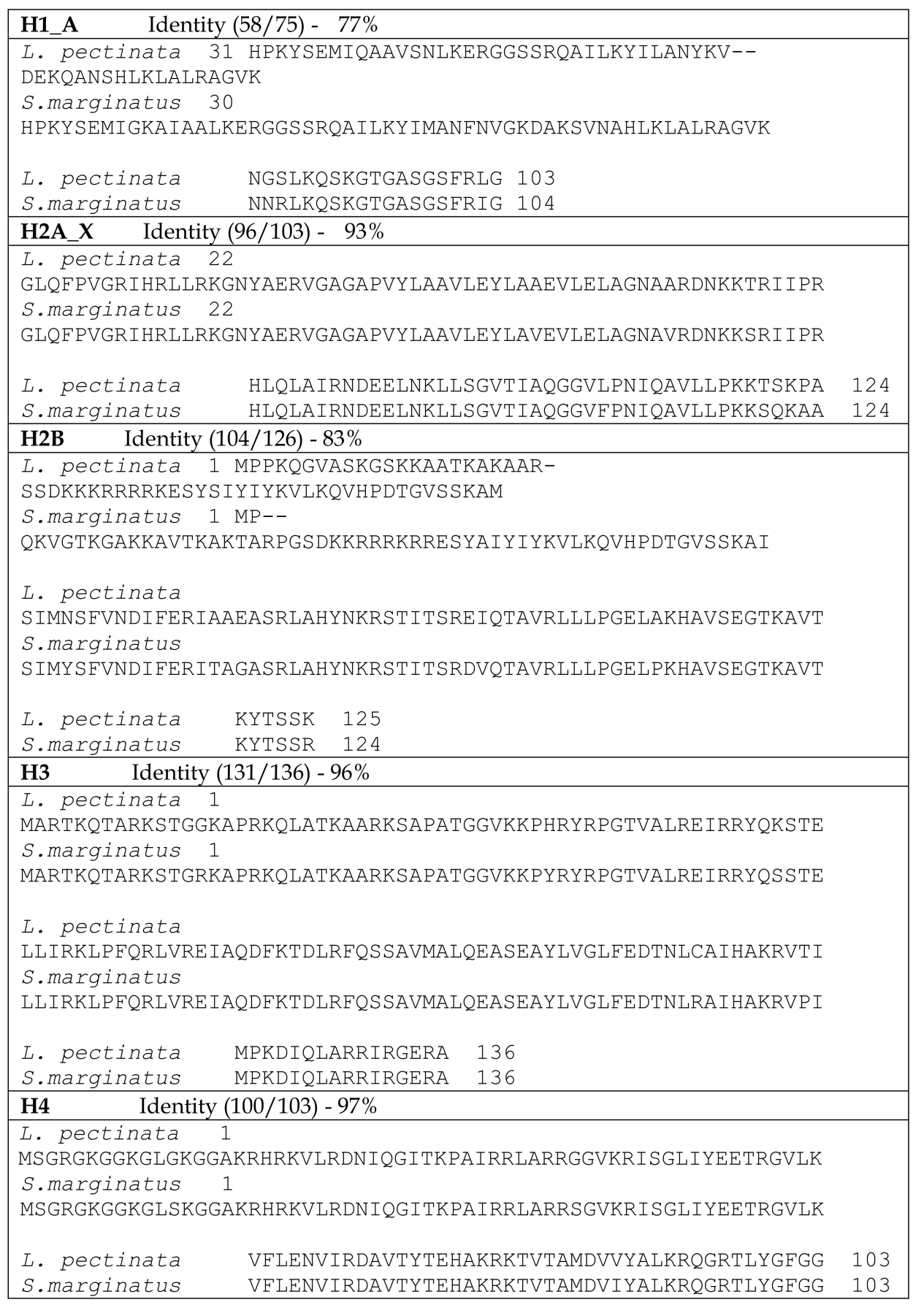

Figure 1. BLASTP alignments between histone protein sequences from Lucina pectinata and Solen marginatus. Areas of sequence identity are highlighted in gray. 
Table 3. Summary of properties of Lucina pectinata histone proteins.

\begin{tabular}{|c|c|c|c|c|c|c|}
\hline $\begin{array}{c}\text { Type } \\
\text { of Histone }\end{array}$ & $\begin{array}{l}\text { Protein } \\
\text { Size }^{1}\end{array}$ & $\mathrm{pI}^{2}$ & $\mathbf{M W}^{3}$ & $\begin{array}{l}\text { Solen Marginatus } \\
\text { Protein Size }^{3}\end{array}$ & $\begin{array}{l}\text { Solen Marginatus } \\
\text { Protein } \mathrm{pI}^{2}\end{array}$ & $\begin{array}{c}\text { Solen Marginatus } \\
\text { Protein } \mathrm{MW}^{3}\end{array}$ \\
\hline H1_A & 186 & 10.94 & 19,658 & \multirow{2}{*}{190} & \multirow{2}{*}{11.18} & \multirow{2}{*}{19,918} \\
\hline H1_B & 179 & 11.29 & 18,750 & & & \\
\hline $\mathrm{H} 3$ & 136 & 11.27 & 15,388 & 136 & 11.47 & 15,521 \\
\hline $\mathrm{H} 4$ & 103 & 11.36 & 11,367 & 103 & 11.36 & 11,441 \\
\hline H2A_W & 135 & 10.12 & 14,687 & \multirow{4}{*}{125} & \multirow{4}{*}{10.90} & \multirow{4}{*}{13,435} \\
\hline H2A_X & 126 & 10.90 & 13,415 & & & \\
\hline H2A_Y & 127 & 10.58 & 13,377 & & & \\
\hline H2A_Z & 125 & 10.62 & 13,379 & & & \\
\hline $\mathrm{H} 2 \mathrm{~B}$ & 125 & 10.52 & 13,855 & 124 & 10.71 & 13,837 \\
\hline
\end{tabular}

${ }^{1}$ amino acid length of polypeptide; ${ }^{2} \mathrm{pI}$, isoelectric point; ${ }^{3} \mathrm{MW}$, molecular weight;

The discontinuous SDS-PAGE analysis showed that there are additional protein bands for the histones isolated from the mantle tissue (Figure 2). This could be due to the presence of histone variants, since many organisms possess multiple copies of histone gene clusters, which could give rise to non-allelic variation [21,22], or post-translational modifications, degradation or co-purification of abundant non-histone proteins.

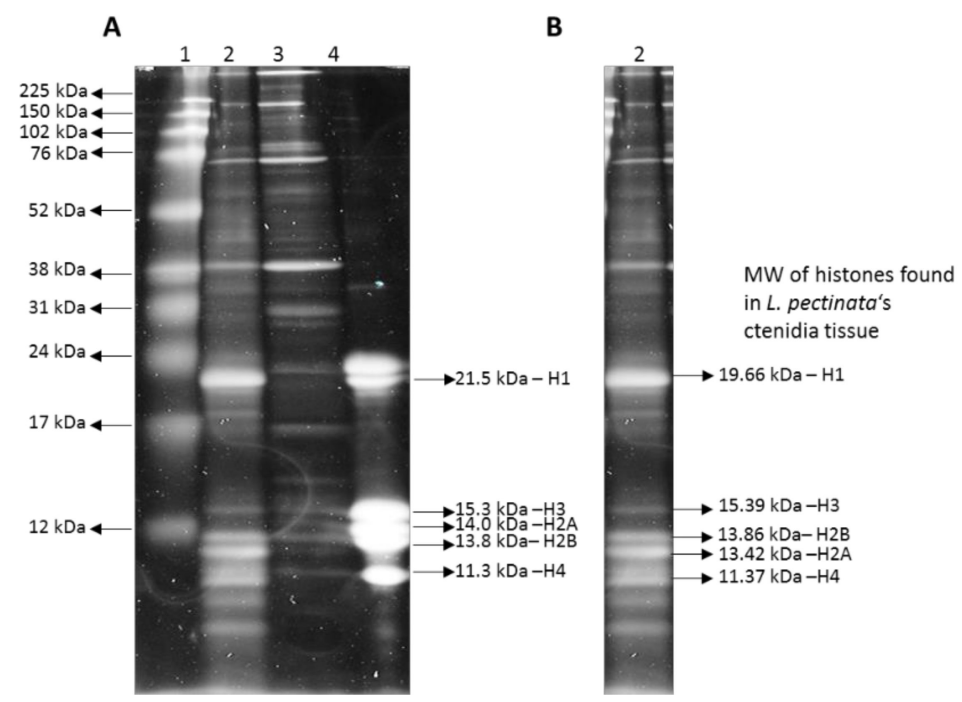

Figure 2. Discontinuous SDS-PAGE gel with isolated histones from Lucina pectinata's ctenidia and mantle tissues. (A) Lane 1-Broad Range rainbow protein ladder (Amersham), Lanes 2 and 3-histones from L. pectinata tissue; (2) ctenidia; (3) mantle; (4) histones from Calf Thymus (Sigma). (B) Lane with histones extracted from L. pectinata ctenidia (lane 2 in section A) with the predicted molecular weights of $\mathrm{H} 1, \mathrm{H} 2 \mathrm{~A}, \mathrm{H} 2 \mathrm{~B}, \mathrm{H} 3$ and $\mathrm{H} 4$.

Furthermore, sequence analysis verified the presence of two $\mathrm{H} 1$ and four $\mathrm{H} 2 \mathrm{~A}$ variants, most were verified by Sanger dideoxy terminator sequencing of RT-PCR products, resulting in an identical match with those sequences obtained from the draft genome and transcriptome assemblies. Alignments of the two H1 (H1_A and H1_B) and four H2A (H2A_W, H2A_X, H2A_Y and H2A_Z) proteins identified are shown in Figure 3, where the two $\mathrm{H} 1$ proteins are only $49.8 \%$ identical, with 101 identical and 31 similar amino acids, whereas the four $\mathrm{H} 2 \mathrm{~A}$ proteins had an overall identity of $42.7 \%$, with 59 identical and 30 similar residues.

With the draft genome assembly, we were able to identify at least one histone of each group, however, we selected only those sequences that contained a complete ORF, several sequences that had partial coding sequences were not considered (Figures 4-8). Hence, despite the fact we have a large number of contigs, the draft genome assembly is adequate for the identification of relatively 
short genes. Two contigs had overlapping sequences, which when joined resulted in a larger contig harboring both an $\mathrm{H} 4$ and an $\mathrm{H} 2 \mathrm{~B}$ gene (Figure 9), which suggests that the L. pectinata histone genes may be organized in the typical clusters seen in other organisms, preserving the common gene order as well [22]. The sequences obtained were submitted to Genbank (Histone_1.A: MH760403; Histone_1.B: MH760404; Histone_2B MH760405; Histone_2A.W MH890684, Histone_2A.X MH760406; Histone_2A.Y MH760407; Histone_2A.Z MH890685, Histone_3 MH760408; Histone_4 MH760409).

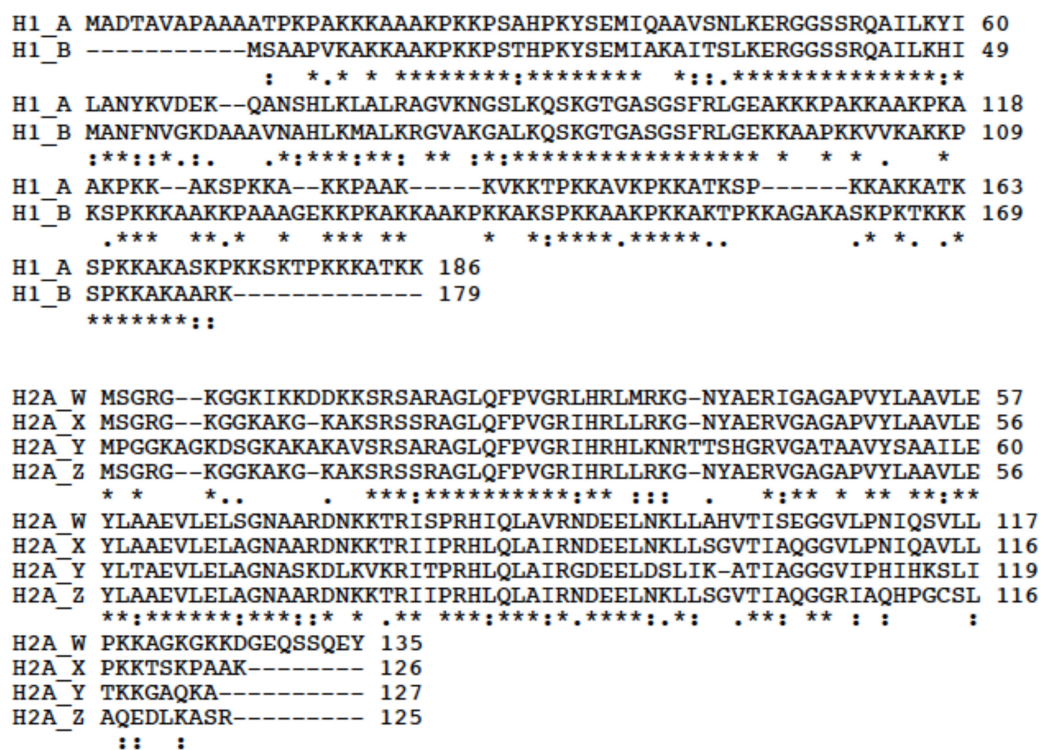

Figure 3. Multiple Alignments of the two Lucina pectinata $\mathrm{H} 1$ and the four $\mathrm{H} 2 \mathrm{~A}$ amino acid sequences. These alignments were generated using cluster analysis of the pairwise alignments with the CLUSTAL Omega tool available at https:/ /www.uniprot.org/align/.
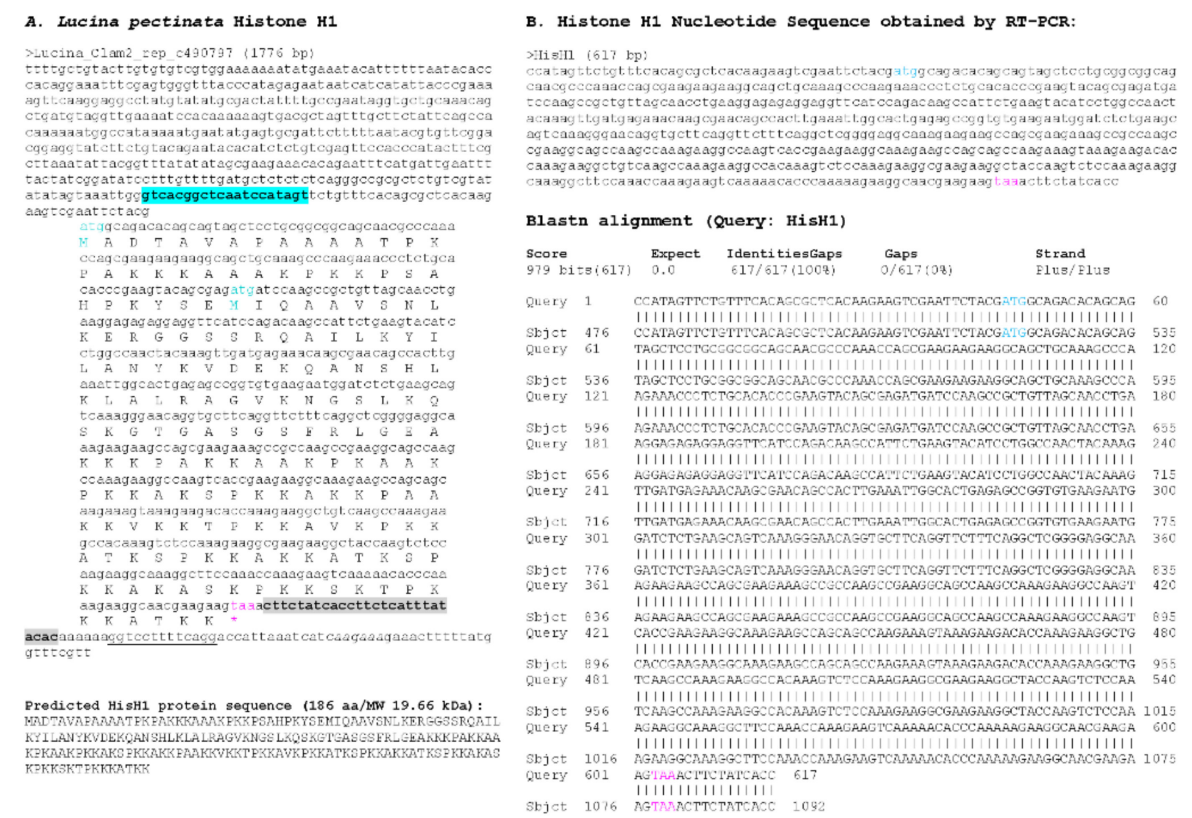

Figure 4. Histone H1_A sequence found in Lucina pectinata genome assembly. (A) One of the two H1-like nucleotide sequences obtained from the BLASTN searches against the L. pectinata genome assembly using the $\mathrm{H} 1$ nucleotide sequence from S. marginatus is shown, including the coding region, the predicted protein sequence and its molecular weight (MW). (B) The nucleotide sequence obtained by Sanger sequencing of RT-PCR products followed by the BLASTN alignment of the cDNA to the genomic sequence, showing a perfect match between the two sequences. Primers used in RT-PCR are highlighted in cyan and grey. Start (cyan) and stop (pink) codons are indicated. 


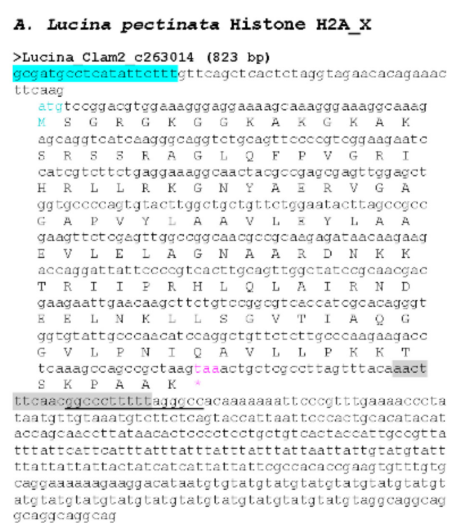

Predicted HisH2A protein sequence $(126 \mathrm{aa} / 13.42 \mathrm{kDa})$ MSGRCKGCKAKGKAKSRSSRACLOE EYGERIHRLLRKGNYAERVGAGADVY

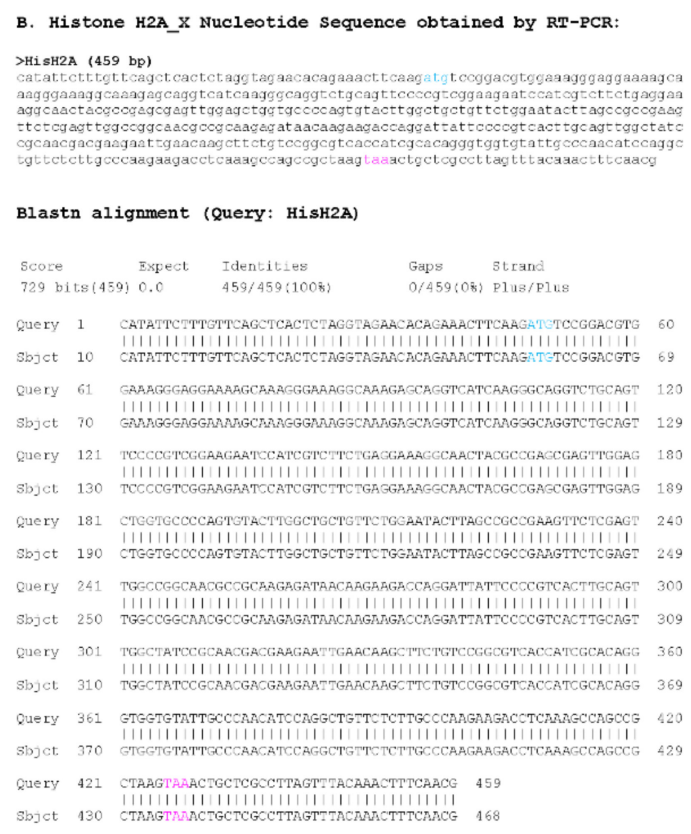

Figure 5. Histone H2A_X sequence found in Lucina pectinata genome assembly. (A) One of the four H2A-like nucleotide sequence obtained from the BLASTN searches against the L. pectinata genome assembly using the H2A nucleotide sequence from S. marginatus is shown, including the coding region, the predicted protein sequence and its molecular weight (MW). Primers used in RT-PCR are highlighted in cyan and grey. Start (cyan) and stop (pink) codons are indicated. (B) The nucleotide sequence obtained by Sanger sequencing of RT-PCR products followed by the BLASTN alignment of the cDNA to the genomic sequence, showing a perfect match between the two sequences.
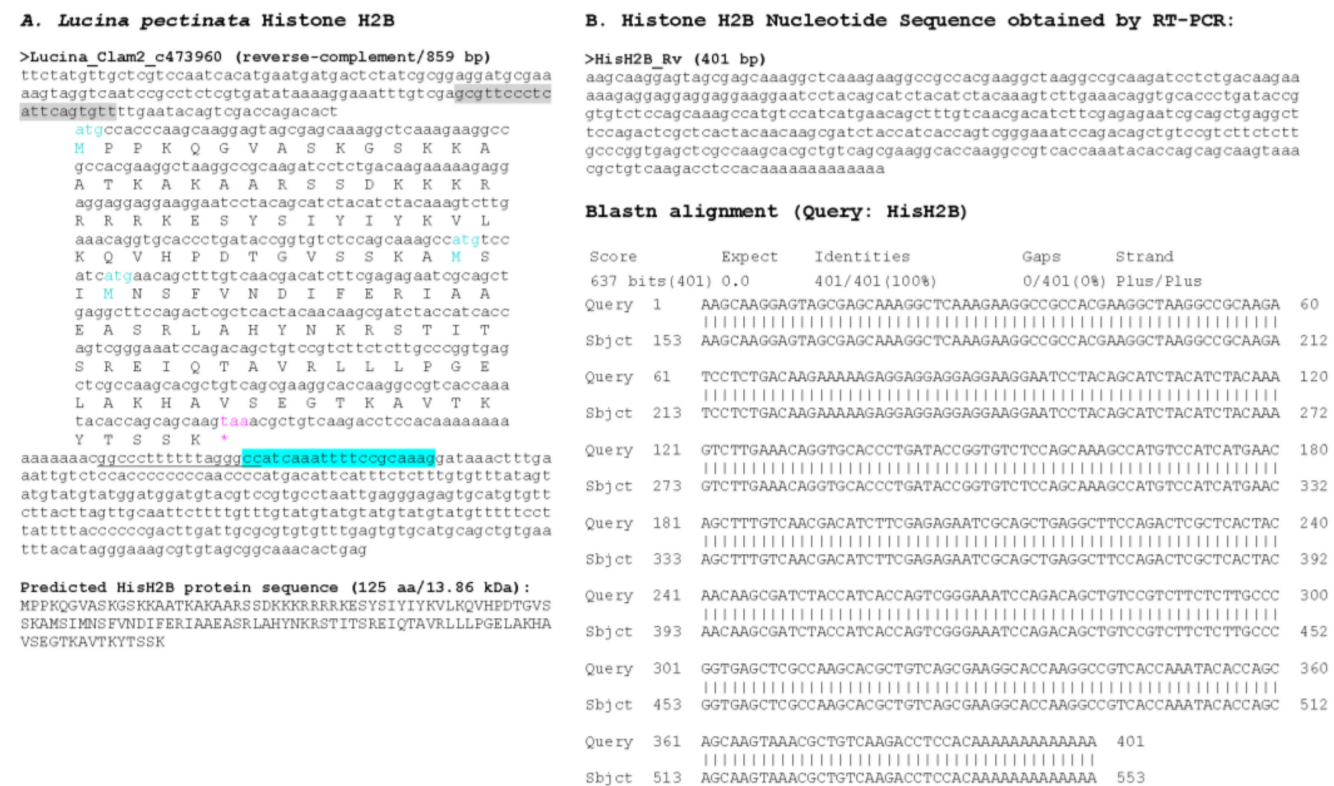

Figure 6. Histone H2B sequence found in Lucina pectinata genome assembly. (A) Histone H2B nucleotide sequence obtained from the BLASTN searches against the L. pectinata genome assembly using the $\mathrm{H} 2 \mathrm{~B}$ nucleotide sequence from S. marginatus is shown, including the coding region, the predicted protein sequence and its molecular weight (MW). (B) The nucleotide sequence obtained by Sanger sequencing of RT-PCR products followed by the BLASTN alignment of the cDNA to the genomic sequence, showing a perfect match between the two sequences. Primers used in RT-PCR are highlighted in cyan and grey. Start (cyan) and stop (pink) codons are indicated. 
A. Sequence for Histone H3

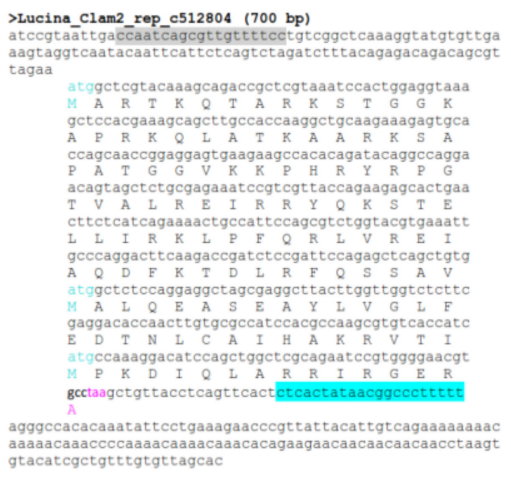

Predicted Histone H3 protein sequence $(136 \mathrm{aa} / 15.39 \mathrm{kDa} /$ ELITRSTGGKAPRRQLATKAARKSAPATGGVKKPHRYRPGTVALREIRRY
B. Sequence obtained by RT-PCR:

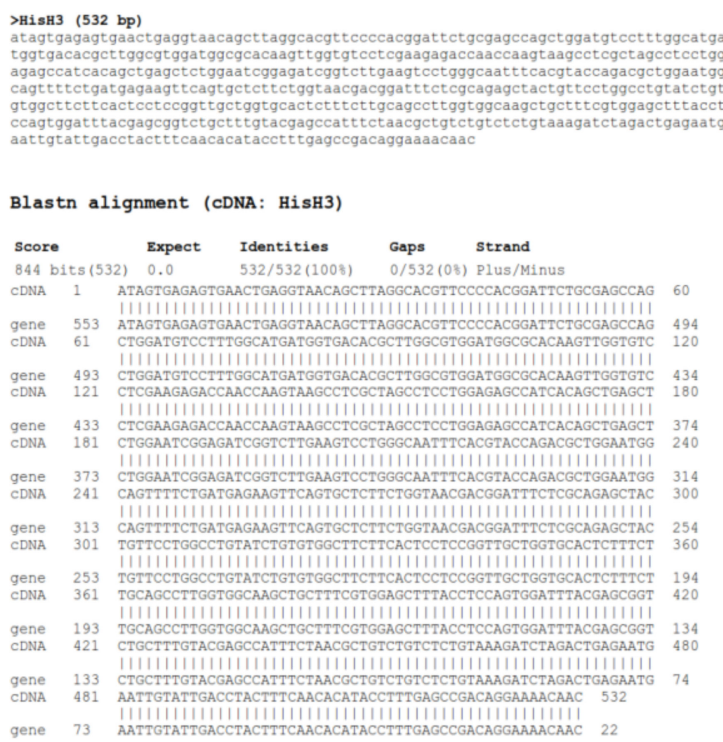

Figure 7. Histone $\mathrm{H} 3$ sequence found in Lucina pectinata genome assembly. (A) The $\mathrm{H} 3$ nucleotide sequence obtained from the BLASTN searches against the L. pectinata genome assembly using the H3 nucleotide sequences from S. marginatus and the partial coding region sequence of $\mathrm{H} 3$ from L. pectinata is shown with the ORF translation, the predicted protein sequence and its molecular weight (MW). (B) The sequence obtained by Sanger sequencing of RT-PCR products by the BLASTN alignment to the genomic sequence, showing a perfect match between the two sequences. Primers used in RT-PCR are highlighted in cyan and grey. Start (cyan) and stop (pink) codons are indicated.

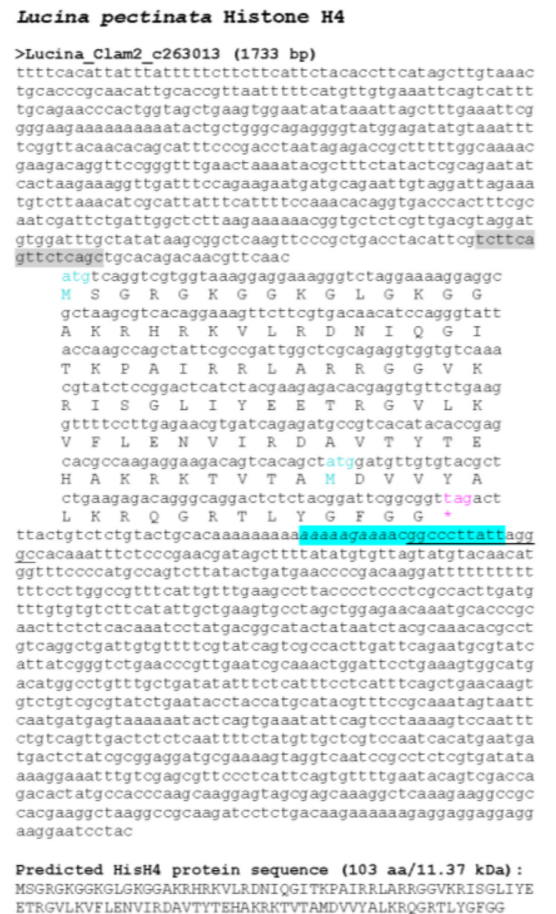

Histone H4 Nucleotide Sequence obtained by RT-PCR:

$>$ HisH4_Rv (295 BP)

cacaggaaagttctt og tgacaacatccagggt at taccaagccagctattogccgattgget cgcagaggtggtg tgcaacogtatctccggactcatctacg aagagacacgagg gettctgaaggtettccttgagaacg tgatcagag ggcaggact ctcracggattcggcggt tagact ttactgtctctgtactgcaa toa

Blastn alignment (Query: HisH4)

Score Expect Identities Gaps Strand $\begin{array}{llllll}\text { Query } 1 & \text { CACAGGAAGTTCTTCGTGACAACATCCAGGGTATTACCAAGCCAGCTATTCGCCGATTG } 60\end{array}$ Sbjet 613 CACAGGAAGTTCTTCGTGACAACATCCAGGGTATACCAAGCCAGCTATTCGCCGATTG 672

Query 61 GCTCGCAGAGGTGGTGTCAAACGTATCTCCGGACTCATCTACGAAGAGACACGAGGTGTT 120 Sbjet $673 \begin{aligned} & 11111111111111111111111111111111111111111111111111111 \\ & \text { GCTCGCAGAGGTGGTTCAAAGTATCTCCGGACTCATCTACGAAGAGACACGAGGTGT }\end{aligned}$

Que ry 121 CTGAAGGTTTTCCTTGAGAACGTGATCAGAGATGCCGTCACATACACCGAGCACGCCAAG 180

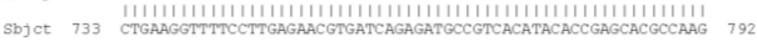

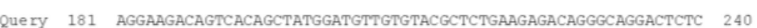

$\begin{array}{llllll}\text { Que ry } & 181 & \text { AGGAAGACAGTCACAGCTATGGATGTTGTGTACGCTCTGAAGAGACAGGGCAGGACTCTC } & 240 \\ \text { Sbjet } & 193 & 1111111111111111111111111111111111111111111111111111 & \text { AGGAAGACAGTCACAGCTATGGATGTTGTTACGCTCTGAAGAGACAGGGCAGGACTCTC } & 852\end{array}$

Query 241 TACGGATTCGGCGGTTAGACTTTACTGTCTCTGTACTGCAAAAAAAAAAAAAAAA 295

Sbjet 853 TACGGATTCGCGGTTAGACTTTACTGTCTCTGTACTGCACAAAAAAAAAAAAAA 907

Figure 8. Histone H4 sequence found in L. pectinata genome assembly. (A) The H4 nucleotide sequence obtained from the BLASTN searches against the L. pectinata genome assembly using the $\mathrm{H} 4$ nucleotide sequences from $S$. marginatus is shown, with the ORF translation, the predicted protein sequence and its molecular weight (MW). Primers used in RT-PCR are highlighted in cyan and grey. Start (cyan) and stop (pink) codons are indicated. (B) The sequence obtained by Sanger sequencing of RT-PCR products by the BLASTN alignment to the genomic sequence, showing a perfect match between the two sequences. 


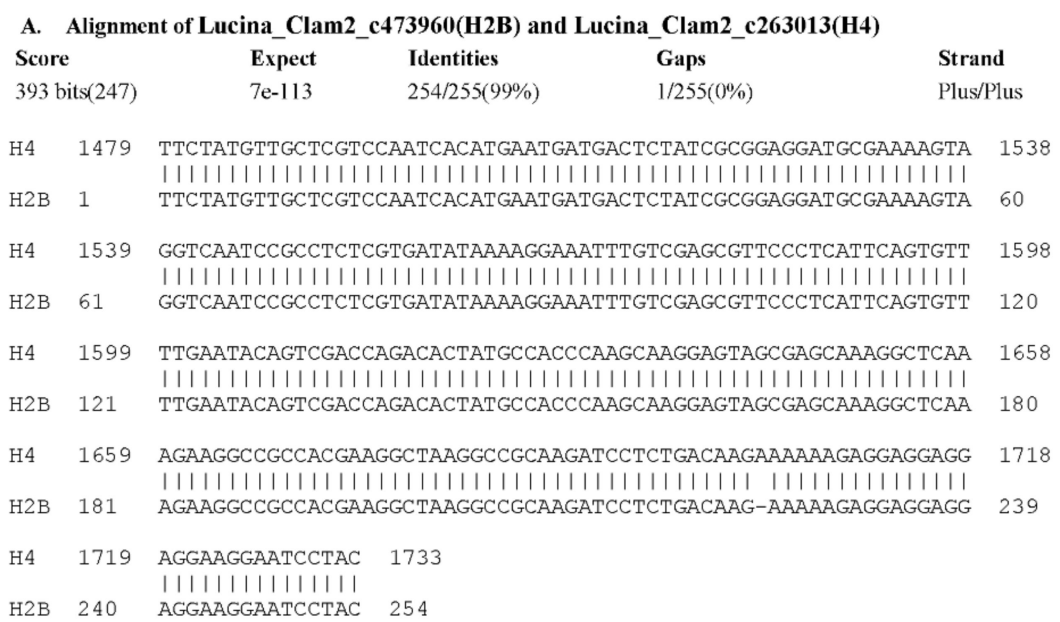

\section{B. Contig Sequence [Lucina_Clam2_c473960(H2B)+Lucina_Clam2_c263013(H4)]}

ttttcacattattattttcttcttcattctacaccttcatagcttgtaaactgcaccegcaacattgcaccgttaatttttcat gttgtgaaattcagtcattttgcagaacccactggtagctgaagtggaatatataaattagctttgaaattcggggaagaaaaaa aatactgctgggcagaggggtatggagatatgtaaattttcggttacaacacagcatttcccgacctaatagagaccgctttttg gcaaaacgaagacaggttccgggtttgaactaaaatacgctt ctatactcgcagaatatcactaagaaaggttgatttccagaag aatgatgcagaattgtaggattagaaatgtcttaaacatcgcattatttcattttccaaacacaggtgacccactttcgcaatcga ttctgattggctcttaagaaaaacggtgctctcgttgacgtaggatgtggatttgctatataagcggctcaagttcccgctcacc tacattcgtcttcagttctcagctgcacagacaacgttcaacatgtcaggtcgtggtaaaggaggaaagggtctaggaaaaggagg cgctaagcgtcacaggaagttcttcgtgacaacatccagggtattaccaagccagctattcgccgattggctcgcagaggtggtg tcaaacgtatctccggactcatctacgaagagacacgaggtgttctgaaggttttccttgagaacgtgatcagagatgccgtcaca taca ccgagcacgccaagaggaagacagt cacagctatggatgttgtgtacgctct gaagagacagggcaggactctctacggatt cggcggttagactttactgtctctgtactgcacaaaaaaaaaaaagaaacggcccttattagggccacaa tttctcccgaac gatagctttatatgtgttagtatgtacaacatggtttccccatgccagtcttatactgatgaacccogacaagattuttttt tttccttggccgtttcattgtttgaagccttacccctccctcgccacttgatgtttgtgtgtcttcatattgctgaagtgcctagc tggagaacaatgcacccgcaacttctctcacaatcctatgacggcatactataatctacgcaaacacgcctgtcaggctgattg tgttttcgtatcagtcgccacttgattcagaatgcgtatcattatcgggtctgaacccgttgaatcgcaaactggatcctgaaag tggcatgacatggcctgtttgctgatatattctcattcctcatttcagctgaacaagtgtctgtcgcgtatctgaatacctacc atgcatacgtttccgcaatagtaattcaatgatgagtaaaaatactcagtgaaatattcagtcctaaagtccaatttctgtca gttgactctctcalt TTCTATGTTGCTCGTCCAATCACATGAATGATGACTCTATCGCGGAGGATGCGAAAAGTAGGTCAATCCG CCTCTCGTGATATAAAAGGAAATTTGTCGAGCGTTCCCTCATTCAGTGTTTTGAATACAGTCGACCAGACACगATECCACCCAAGC

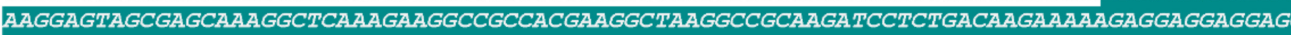
AAGGAATCCTACAgcatctacat ctacaaagtcttgaaacaggtgcaccctgataccggtgtctccagcaaagecatgtccatcat

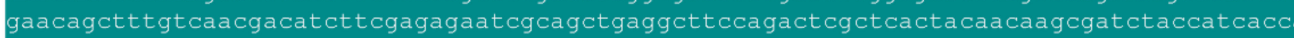
tcgggaaatccagacagctgtccgtcttctcttgcccggtgagctcgccaagcacgctgtcagcgaaggcaccaaggccgtcac aatacaccagcagcaagtaalacgctgtcaagacctccacaaaaaaaaaaaacggccetttttagggccatcaaattttccg caaggataaactttgaattgtctccaccccccccaaccccatgacattcatttctcttgtgtttatagtatgtatgtatggat ggatgtacgtccgtgcctaattgagggagagtgcatgtgttcttacttagttgcaattctttgtttgtatgtatgtatgtatgta tgtttttccttattttaccccccgacttgattgcgcgtgtgtttgagtgtgcatgcagctgtgaatttacatagggaaagcgtgta gcggcaacactgag

C.

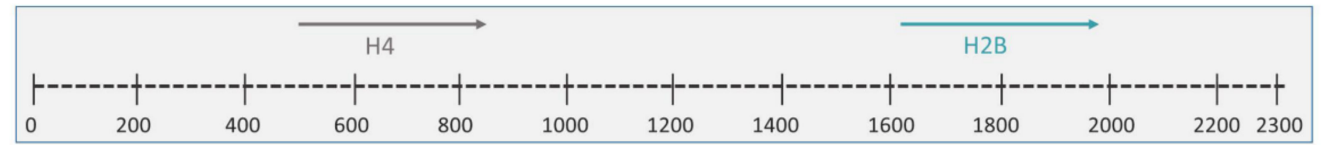

Figure 9. The $\mathrm{H} 4$ gene precedes the $\mathrm{H} 2 \mathrm{~B}$ gene in the Lucina pectinata genome. (A) BLASTN analysis between sequences containing the $\mathrm{H} 4$ and $\mathrm{H} 2 \mathrm{~B}$ genes obtained from the draft genome show an overlap of $255 \mathrm{bp}$, suggesting these two sequences can form a larger contig. (B) The contig containing the H4 and $\mathrm{H} 2 \mathrm{~B}$ genes resulted in a $2337 \mathrm{bp}$ long sequence. The $\mathrm{H} 4$ coding region is highlighted in gray and the H2B coding sequence is highlighted in teal. The common overlapping region of $255 \mathrm{bp}$ is indicated in bold/italic uppercase letters. (C) Schematic representation of the H4 (gray colored arrow) and H2B (teal colored arrow) genes localization, arrows indicate the direction of transcription $\left(5^{\prime} \rightarrow 3^{\prime}\right)$.

The histone RNA sequences retrieved from the transcriptome assembly were partially confirmed by RT-PCR. All histone mRNAs had the typical palindromic sequence (underlined in Figures 4-8) that is capable of forming a stem-loop structure, typical of replication-dependent (RD) histone genes, close to the stop codon. The conserved central domain found in histone H1 proteins was also found in the two $\mathrm{H} 1$ variants we identified in our study. At the nucleotide level, Purine-rich elements (in italics 
in Figures 4-8) were only detected close to the palindromic sequence in the H1_A, H2A_X, H3 and $\mathrm{H} 4$, but their position was either slightly more distant to the palindromic sequence (H1_A, H2A_X and $\mathrm{H} 3$ ) or immediately preceding it (H4). The lack of these conserved sequences in the $3^{\prime}$ end of the H1_B gene suggest it may belong to the replication-independent (RI) H1 isoforms, but we did not detect a polyadenylation signal, as seen in the mussel Mytilus galloprovincialis histone H1 "orphon" genes [23]. Hence, the histone H1_B gene expression pattern warrants further study to determine if its unusual $3^{\prime}$ UTR has functional significance.

\subsection{Multiple Sequence Alignment of Histone H1_A Variant Sequence Shows Conservation of Amino Acids Among Species}

A BLAST search using the UniProtKB database with the H1_A from L. pectinata amino acid sequence as query was used to select sequences for alignment (Figure S1). The species selected include: mammals, mollusks, insects, fish, worms, reptiles and amphibians (Table S1). The multiple sequence alignment shows some gaps but most importantly shows regions where a large number of amino acids are conserved among the different species as shown in Figure S2. Among these amino acids the most conserved, which are shown in a darker shade of blue, are: lysine, valine, glycine, alanine, serine, tyrosine, methionine among others of less conservation (lightest shade of color). The most conserved amino acid is, as expected, lysine $(\mathrm{K})$, a positively charge amino acid typically enriched in histones and involved in epigenetic histone modifications.

\subsection{Phylogenetic Analysis of Lucina Pectinata Histone H1 Shows a Common Ancestor Among Other Histone H1 Proteins from Mollusks and Other Species}

We built a phylogenetic gene tree using the Maximum Likelihood Method (ProML) (PHYLIP) [19], and the results were visualized using the iTOL server [20]. As shown in Figure 11, our query sequences have a common ancestor that is closer in evolution to other marine organism, insects and birds. The results show that our query sequences are also related to the S. marginatus H1 protein, as expected, and to other bivalves or marine organisms (such as: sponges, mussels, other clams, oysters, octopus, crabs). L. pectinata H1_A and H1_B proteins are close in relationship with other protostome organisms (other mollusk, insects and worms). In comparison with studies of the razor clam Solen marginatus [1], another bivalve mollusk, our tree shows some similarities in evolutionary relationships between protostomes and deuterostomes as shown in Figure 10. Additionally, we can assume that the L. pectinata $\mathrm{H} 1$ proteins have a common ancestor not only with one another but also with $S$. marginatus, this relationship is represented in clades, which determine all the descendants of one common ancestor. Furthermore, comparing L. pectinata's proteins with those from S. marginatus, H1_B from L. pectinata has a closer evolutionary relationship than H1_A to the S. marginatus H1. It is interesting that both H1_A and H1_B are both outgroups of their respective nodes. This finding suggests that H1_B is more evolved than H1_A, and also that H1_A has reached its highest evolutionary point in contrast to H1_B which kept on developing like the H1 from S. marginatus. As a summary of the results obtained for our phylogenetic analysis, our query proteins have an evolutionary relationship with other protostome organisms, but in contrast, they are farther apart in evolution from deuterostome organisms (including mammals). We can only assume that these proteins have evolved differently depending on the organism and also on the environment they are exposed to. Further studies of invertebrate hemoglobins are needed to better understand the evolution of histone $\mathrm{H} 1$, in addition to the evolution of histone $\mathrm{H} 2 \mathrm{~A}$ and its variants among species. 


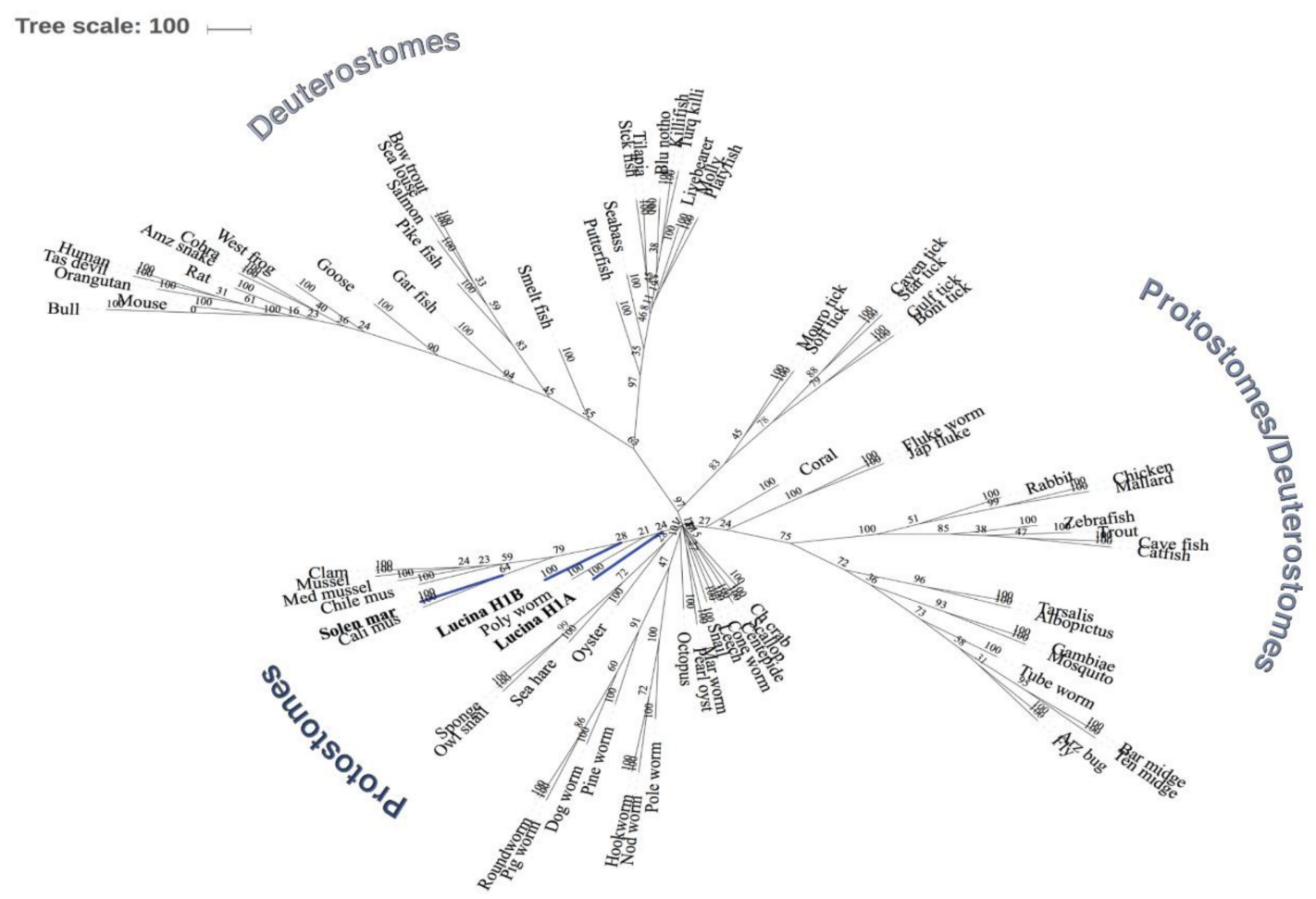

Figure 10. Phylogenetic Analysis between Histones H1 proteins of Lucina pectinata and Histone H1 protein from various species. An unrooted maximum likelihood (ProML) phylogenetic gene tree model was built from the CLUSTALW alignment. Numbers for nodes (interior of branches) represent bootstrap values based on 100 replicates. The L. pectinata query sequences (H1_A and H1_B) and the S. marginatus $\mathrm{H} 1$ protein sequence are shaded in blue. The legend provided represents the subtaxons of protostomes and deuterostomes.

\section{Discussion}

In order to validate the contigs of the genome assembly by identifying new proteins, we searched for genes that lacked introns and focused on the histone genes. The genome assembly contained too many contigs, which could be a consequence of several factors: repetitive sequences, polymorphisms, missing data and mistakes [24]. We found many repetitive elements located across L. pectinata genome [7]. From a computational perspective, sequence repeats have always presented technical challenges for sequence alignment and assembly programs, which, in turn, can produce biases and errors when interpreting results [25].

Since repetitive sequences are commonly found in introns rather than exons [26], we chose to search for genes coding for histone proteins, which are short, intron-less genes [27] and we expected that their sequence assembly would be easy and accurate. Histones are found in the somatic cells of all eukaryotic organisms, with the exception of some dinoflagellates [21,22]. In order to find the histone sequences in our genome assembly, we identified homologous sequences from another clam, S. marginatus. With these sequences we were able to retrieve at least one nucleotide sequence for each histone gene with relatively high identities at the nucleotide and predicted protein histone sequence levels for L. pectinata and, as expected, the conservation at protein level was higher than at the nucleotide level. The discontinuous SDS-PAGE analysis of histones isolated from the mantle tissue showed that there are additional polypeptides that could come from histone variants, which we found evidence of at the sequence level for the $\mathrm{H} 1$ and $\mathrm{H} 2 \mathrm{~A}$ genes, due to multiple copies of histone genes in the clam's genome [22]. Alternatively, the multiple bands detected could be due to post- translational modifications or degradation or co-purification of abundant non-histone proteins. Histone variants are used to produce specialized nucleosomes, for example, the specialization imparted by H2A variants (H2A.X and H2A.Z), in the mussel Mytilus galloprovincialis, constitutes the earliest response to DNA 
damage [28]. Chromatin can be modified by the incorporation of histone variants, which would change local chromatin structure by promoting nucleosome subunit exchange to facilitate cellular processes such as transcription or during development [29]. Since our L. pectinata genome overall assembled size was estimated at $1.3 \mathrm{~Gb}$ and the estimated size of its genome is about $1.6 \mathrm{~Gb}$, it is likely that we did not identify all of its histone gene sequences. Nevertheless, the sequence conservation at the nucleotide and protein levels showed that the clam histone $\mathrm{H} 1$ sequences have evolved more than their mammalian counterparts, which would be expected from an organism that lives in an extreme, sulfide-rich environment.

Our phylogenetic analysis is based on an unrooted tree which is an important step towards obtaining a representation of the evolutionary history of our selected histone H1 proteins. This representation shows us that the L. pectinata's H1 proteins have an evolutionary relationship to other invertebrate organisms. As already shown, even though histone $\mathrm{H} 1$ proteins have conserved regions in their sequence, it is also the most variable of the histone proteins among species. This information can be seen in our phylogenetic analysis which demonstrates the relationship of the L. pectinata $\mathrm{H} 1$ proteins among different species. In our analysis, our query proteins fall closely in evolution to other $\mathrm{H} 1$ proteins of mollusk organisms (such as S. marginatus). In contrast, they are further apart in their evolutionary relationship to vertebrate species (such as mammals), other marine species (fish) and a variety of insects. Thus, even though histone H1 proteins have highly conserved regions that may not allow dissection of evolutionary relationships among other $\mathrm{H} 1$ proteins of a variety of species, when using the entire amino acid sequences, one may observe differences in evolutionary relationships between histone $\mathrm{H} 1$ proteins of various species. Future directions will include the construction of a rooted phylogenetic tree (from our unrooted tree) to define a clear view of the direction of evolution changes of histone $\mathrm{H} 1$ among various species and phylogenetic analyses of the histone H2A variants identified in our study.

\section{Conclusions}

In conclusion, we were able to identify histone gene sequences of each of the five types of histones in the Lucina pectinata genome assembly generated by semiconductor sequencing. These sequences were amplified by RT-PCR and sequenced. All of them had an identical match with those sequences obtained from the genome assembly. This suggests that, despite the fact that the assembly has many contigs, the clam genome and transcriptome assemblies are adequate for the identification of relatively short genes. In order to obtain a better genome assembly, new mate-paired libraries would be required to resolve regions with repetitive sequences. These studies will allow us to perform future studies on the epigenetic changes that may arise in chromatin proteins like the histones upon exposure to extreme environments.

We have been able to characterize histone genes and several gene variants from a clam that can withstand the extreme sulfide-rich environments of tropical mangroves and learn from the phylogenetic analysis how environmental influences have caused the most variable histone genes to develop gene variants that showed intra-species variability. In working with this clam, we had to overcome problems associated with a high repetitive sequence content as well as the nature of the sample, which often proved challenging for obtaining DNA or RNA adequate for molecular analyses. Nevertheless, we have produced two valuable resources for the academic community which can be mined to study gene and genome structure and evolution.

Supplementary Materials: The following are available online at http:/ / www.mdpi.com/1660-4601/15/10/2170/ s1, Figure S1: Multiple Sequence Alignment generated using CLUSTALW; Figure S2: Multiple sequence alignment of the conserved central globular domain of histone H1s from 80 different species; Table S1: Complete List of H1 Protein Sequences Used for the Multiple Sequence and Phylogenetic Analyses.

Author Contributions: Individual contributions are as follows: conceptualization, C.L.C., I.M.M.R., R.R.G.-M. and J.L.G.; methodology, C.L.C., I.M.M.R., R.R.G.-M., Y.R.P.; software, I.M.M.R, Y.R.P., R.R.G.-M. and A.J.R.; validation, I.M.M.R., Y.R.P. C.L.C.; formal analysis, C.L.C., I.M.M.R., Y.R.P., R.R.G.-M., A.J.R.; resources, C.L.C., J.L.G. and A.J.R.; data curation, I.M.M.R.; writing-original draft preparation, C.L.C., I.M.M.R. and Y.R.P.; 
writing-review and editing, C.L.C.; supervision, C.L.C., J.L.G., R.R.G.-M. and A.J.R.; project administration, C.L.C.; funding acquisition, C.L.C., J.L.G., R.R.G.-M., A.J.R. This work was performed in partial fulfillment of the dissertation requirements of I.M.M.R. at the University of Puerto Rico in Mayagüez.

Funding: The following grants provided infrastructure and supplies support: From the UPR-Medical Sciences Campus: NIGMS PR-INBRE grant P20RR16470, RCMI program of the National Institute on Minority Health and Health Disparities (NIMHD) grants G12MD007600 and U54MD007600 and PRCTRC Award Number U54MD007587; from UPR-Mayagüez Campus: NIGMS grant R25GM088023 supported I.M.M.R. This work was partially funded through the U.S. National Institutes of Health, National Institute of General Medical Sciences Minority Access to Research Careers Grants T36-GM-008789, T36-GM-095335. It also received partial support from the Extreme Science and Engineering Discovery Environment (XSEDE) [30], NSF grant OCI-1053575. Specifically, it used the Blacklight [31] and Bridges [32] systems, which are supported by NSF award numbers ACI-1041726 and ACI-1445606 at the Pittsburgh Supercomputing Center. Any opinions, findings, and conclusions or recommendations expressed in this material are those of the author(s) and do not necessarily reflect the views of the National Science Foundation.

Acknowledgments: We acknowledge the support of the University of Puerto Rico Medical Sciences Campus Graduate Assistantships Program to Y.R.P. We thank Hector J. Jirau Colón for technical assistance.

Conflicts of Interest: The authors declare no conflict of interest. The funders had no role in the design of the study; in the collection, analyses, or interpretation of data; in the writing of the manuscript, or in the decision to publish the results.

\section{References}

1. González-Romero, R.; Ausió, J.; Méndez, J.; Eirín-López, J. Histone genes of the razor clam Solen marginatus unveil new aspects of linker histone evolution in protostomes. Genome 2009, 52, 597-607. [CrossRef] [PubMed]

2. Olins, A.L.; Olins, D.E. Spheroid chromatin units (v bodies). Science 1974, 183, 330-332. [CrossRef] [PubMed]

3. Fyodorov, D.V.; Zhou, B.R.; Skoultchi, A.I.; Bai, Y. Emerging roles of linker histones in regulating chromatin structure and function. Nat. Rev. Mol. Cell Biol. 2018, 19, 192-206. [CrossRef] [PubMed]

4. Ponte, I.; Vila, R.; Suau, P. Sequence complexity of histone H1 subtypes. Mol. Biol. Evol. 2003, 20, 371-380. [CrossRef] [PubMed]

5. Thoma, F.; Koller, T. Influence of histone H1 on chromatin structure. Cell 1997, 12, 101-110. [CrossRef]

6. Szerlong, H.J.; Hansen, J.C. Nucleosome distribution and linker DNA: Connecting nuclear function to dynamic chromatin structure. Biochem. Cell Biol. 2011, 89, 24-34. [CrossRef] [PubMed]

7. Eirín-López, J.; Fernanda, M.; González-Tizón, A.; Martínez, A.; Méndez, J. Birth-and-Death Evolution with Strong Purifying Selection in the Histone H1 Multigene Family and the Origin of orphon H1 Genes. Mol. Biol. Evol. 2004, 21, 1992-2003. [CrossRef] [PubMed]

8. Montes-Rodríguez, I.M.; Cadilla, C.L.; González-Méndez, R.; López-Garriga, J.; Ropelewski, A. De Novo Assembly of Lucina pectinata Genome using Ion Torrent Reads. In Proceedings of the Practice and Experience in Advanced Research Computing 2017 Proceedings (PEARC17), New Orleans, LA, USA, 9-13 July 2017. [CrossRef]

9. Chomczynski, P.; Sacchi, N. Single-Step Method of RNA Isolation by Acid Guanidinium Extraction. Anal. Biochem. 1987, 162, 156-159. [CrossRef]

10. Krebs, S.; Fischaleck, M.; Blum, H. A simple and loss-free method to remove TRIzol contaminations from minute RNA samples. Anal. Biochem. 2009, 387, 136-138. [CrossRef] [PubMed]

11. Grabherr, M.G.; Haas, B.J.; Yassour, M.; Levin, J.Z.; Thompson, D.A.; Amit, I.; Adiconis, X.; Fan, L.; Raychowdhury, R.; Zeng, Q.; et al. Full-length transcriptome assembly from RNA-Seq data without a reference genome. Nat. Biotechnol. 2011, 29, 644-652. [CrossRef] [PubMed]

12. Altschul, S.F.; Gish, W.; Miller, W.; Myers, E.W.; Lipman, D.J. Basic Local Alignment Search Tool. J. Mol. Biol. 1990, 215, 403-410. [CrossRef]

13. Altschul, S.F.; Madden, T.L.; Schäffer, A.A.; Zhang, J.; Zhang, Z.; Miller, W.; Lipman, D.J. Gapped BLAST and PSI-BLAST: A new generation of protein database search programs. Nucleic Acids Res. 1997, 25, 3389-3402. [CrossRef] [PubMed]

14. Johnson, M.; Zaretskaya, I.; Raytselis, Y.; Merezhuk, Y.; McGinnis, S.; Madden, T.L. NCBI BLAST: A better web interface. Nucleic Acids Res. 2008, 36, W5-W9. [CrossRef] [PubMed] 
15. Wheeler, D.L.; Church, D.M.; Federhen, S.; Lash, A.E.; Madden, T.L.; Pontius, J.U.; Schuler, G.D.; Schriml, L.M.; Sequeira, E.; Tatusova, T.A.; et al. Database resources of the National Center for Biotechnology. Nucleic Acids Res. 2003, 31, 28-33. [CrossRef] [PubMed]

16. Untergasser, A.; Nijveen, H.; Rao, X.; Bisseling, T.; Geurts, R.; Leunissen, J.A.M. Primer3Plus, an enhanced web interface to Primer3. Nucleic Acids Research. [CrossRef] [PubMed]

17. Thomas, J.O.; Kornberg, R.D. An octamer of histones in chromatin and free in solution. Proc. Natl. Acad. Sci. USA 1975, 72, 2626-2630. [CrossRef] [PubMed]

18. Waterhouse, A.M.; Procter, J.B.; Martin, D.M.A.; Clamp, M.; Barton, G.J. Jalview Version 2-A multiple sequence alignment editor and analysis workbench. Bioinformatics 2009, 25, 1189-1191. [CrossRef] [PubMed]

19. Felsenstein, J. Inferring phylogenies from protein sequences by parsimony, distance, and likelihood methods. Methods Enzymol. 1996, 266, 418-427. [PubMed]

20. Letunic, I.; Bork, P. Interactive tree of life (iTOL) v3: An online tool for the display and annotation of phylogenetic and other trees. Nucleic Acids Res. 2016, 44, W242-W245. [CrossRef] [PubMed]

21. Van Holde, K.A. Chapter 4: The Proteins of Chromatin. I. Histones. In Chromatin; Richi, A., Ed.; Springer-Verlag: New York, NY, USA, 1988; pp. 69-168.

22. Maxson, R.; Cohn, R.; Kedes, L.; Mohun, T. Expression and Organization of Histone Genes. Ann. Rev. Genet. 1983, 17, 239-277. [CrossRef] [PubMed]

23. Eirin-López, J.M.; Ruiz, M.F.; Gonález-Tizón, A.M.; Martínez, A.; Ausió, J.; Sánchez, L.; Méndez, J. Common evolutionary origin and birth-and-death process in the replication-independent histone $\mathrm{H} 1$ isoforms from vertebrate and invertebrate genomes. J. Mol. Evol. 2005, 61, 398-407. [CrossRef] [PubMed]

24. Baker, M. De novo genome assembly: What every biologist should know. Nat. Methods 2012, 9, $333-337$. [CrossRef]

25. Treangen, T.J.; Salzberg, S.L. Repetitive DNA and next-generation sequencing: Computational challenges and solutions. Nat. Rev. Genet. 2013, 13, 36-46. [CrossRef] [PubMed]

26. Oki, N.; Yano, K.; Okumoto, Y.; Tsukiyama, T.; Teraishi, M.; Tanisaka, T. A genome-wide view of miniature inverted-repeat transposable elements (MITEs) in rice, Oryza sativa ssp. japonica. Genes Genet. Syst. 2008, 83, 321-329. [CrossRef] [PubMed]

27. Pandey, N.B.; Chodchoy, N.; Liu, T.J.; Marzluff, W.F. Introns in histone genes alter the distribution of $3^{\prime}$ ends. Nucleic Acids Res. 1990, 18, 3161-3170. [CrossRef] [PubMed]

28. González-Romero, R.; Rivera-Casas, C.; Frehlick, L.J.; Méndez, J.; Ausió, J.; Eirín-López, J.M. Histone H2A (H2A.X and H2A.Z) variants in molluscs: Molecular characterization and potential implications for chromatin dynamics. PLoS ONE 2012, 7, e30006. [CrossRef] [PubMed]

29. Mariño-Ramírez, L.; Kann, M.G.; Shoemaker, B.A.; Landsman, D. Histone structure and nucleosome stability. Expert Rev. Proteom. 2005, 2, 719-729. [CrossRef] [PubMed]

30. Towns, J.; Cockerill, T.; Dahan, M.; Foster, I.; Gaither, K.; Grimshaw, A.; Hazlewood, V.; Lathrop, S.; Lifka, D.; Peterson, G.D.; et al. XSEDE: Accelerating scientific discovery. Comput. Sci. Eng. 2014, 16, 62-74. [CrossRef]

31. Nystrom, N.; Welling, J.; Blood, P.; Goh, E.L. Blacklight: Coherent Shared Memory for Enabling Science. In Contemporary High Performance Computing: From Petascale toward Exascale, CRC 2013; Vetter, J.S., Ed.; Chapman and Hall: London, UK, 2013; pp. 431-450.

32. Nystrom, N.A.; Levine, M.J.; Roskies, R.Z.; Scott, J. Bridges: A uniquely flexible HPC resource for new communities and data analytics. In Proceedings of the 2015 XSEDE Conference, Scientific Advancements Enabled by Enhanced Cyberinfrastructure, St. Louis, MO, USA, 26-30 July 2015; p. 30.

(C) 2018 by the authors. Licensee MDPI, Basel, Switzerland. This article is an open access article distributed under the terms and conditions of the Creative Commons Attribution (CC BY) license (http://creativecommons.org/licenses/by/4.0/). 